\title{
Smoking Cessation Behavior in Male Portuguese Californians
}

\author{
Hildemar Dos Santos, Serena Tonstad, Susanne Montgomery, Michael Paalani and Pegah Faed \\ Loma Linda University, School of Public Health, Health Promotion Department
}

\begin{abstract}
The purpose of this study was to identify determinants of smoking cessation in a sample of male Portuguese Californians using data from the Portuguese Study, a dissertation thesis study with a crosssectional design that assessed 141 smokers and 67 ex-smokers of Portuguese origin residing in Southern and Central California recruited from Portuguese community clubs. Socio-demographics, acculturation, health beliefs, stress, and social support for smoking cessation were assessed and measured in this population. Bivariate predictors of becoming an ex-smoker were being married $(\mathrm{p}=.01)$, having a high support index for not smoking $(p<.01)$, having a nonsmoking close friend $(p<.01)$, perception that doctors control health $(\mathrm{p}=.02)$, disagreement with the belief that health occurs by chance $(\mathrm{p}=.01)$, and belief that it is easy to stop smoking $(\mathrm{p}<.01)$. In a multivariate analysis - after controlling for demographic variables, acculturation, and stress variables - ex-smoking status remained associated with having a high support index for not smoking $(\mathrm{p}<.01)$, having a nonsmoking close friend $(\mathrm{p}=.05)$, disagreement with the belief that health occurs by chance $(\mathrm{p}<.01)$ and belief that it is easy to stop smoking $(\mathrm{p}<.01)$. Conclusion: Social support, the belief that health does not occur by chance and self-efficacy were associated with being an ex-smoker in Portuguese Californian males. Smoking cessation programs in this population should address these determinants.
\end{abstract}

(C) 2011 Californian Journal of Health Promotion. All rights reserved.

Keywords: Portuguese Californians, Portuguese Americans, smoking cessation, smoking predictors, smoking behavior

\section{Introduction}

\section{Smoking epidemic}

Smoking is a harmful health behavior that leads to premature disease and death. According to the most recent Surgeon General's Report on Smoking (2010), more than 400,000 deaths in the US are related to smoking every year. Moreover, since the first Surgeon General's report in 1964, smoking has been responsible for more than 12 million deaths in the US (Surgeon General's Report, 2010). Globally, the World Health Organization (2008) reports that smoking caused the death of 100 million people during the 20th century and estimates more than 1 billion deaths for the 21st century. Smoking cessation is one important approach to decreasing disease incidence and mortality in the US (Capewell \& O'Flaherty, 2008) and globally.

\section{Smoking prevalence}

Despite the negative consequences of smoking, it remains prevalent in the US with higher rates for men $(23.5 \%)$ than for women $(17.9 \%)$ CDC, 2010). In California, $17.8 \%$ of men and $10.3 \%$ for women are smokers (Kaiser Family Foundation, 2011). A comparison of smoking rates by ethnic groups shows that rates are similar between Blacks (21.3\%) and Whites (22.0\%), higher in Native Americans $(32.4 \%)$, and lower in Asians (9.9\%) and Hispanics (15.8\%). In 2008, Cuban immigrants had the highest rates of smoking at $21.5 \%$, followed by American-born Mexicans (20.1\%), Puerto Ricans (18.6\%), Central and South Americans (12.8\%), and immigrant Mexicans (11.6\%), with the lowest rates among Dominicans at $10.7 \%$ (American Lung Association, 2008). With disparities among different ethnic groups, there 
is a need for developing smoking prevention and cessation activities that are sensitive to culture (CDC, 2010).

\section{Portuguese and smoking}

There is no data on smoking rates for Portuguese American immigrants; therefore, rates for Hispanics are used as a comparison because the groups share some similarities. James, Navara, Clarke and Lomotey (2005) explain that both Hispanics and Portuguese are from the Iberia Peninsula and have at least two main common factors, the Catholic religion and a strong family bond. Portuguese and Spanish languages are both derived from Latin and are so similar that individuals from both language backgrounds can understand each other with little or no difficulty.

Rates for cigarette smoking are high in Portugal where $30.6 \%$ of males and $11.6 \%$ of females smoke (Precioso, Calheiros, Pereira, Campos, Antunes, Rebelo \& Bonito, 2009). Similarly, in California, based on a needs assessment survey among Portuguese American immigrants, more men than women are smokers, $45.5 \%$ and $16.3 \%$ respectively (Dos Santos, 1999). The leading causes of death in Portugal are cardiovascular diseases and cancer 28,737 and 22,711 deaths in 2003 respectively. Colorectal cancer is the leading type of cancer-related death (14\%) followed by lung cancer $(13.9 \%)$ and stomach cancer (11\%). However, among men the greatest percentage of cancer-related deaths is from lung cancer $(19 \%)$ reflecting the high smoking rates in the country (6th National Conference of Nursing Oncology, 2006).

The percentage of death attributable to smoking in Portugal is $11.7 \%$., but for men, this number is $17.7 \%$. The burden of diseases attributable to smoking is $15.4 \%$ among males in the country. This reflects the high cost that Portuguese males pay for their higher rates of smoking (Borges, Gouveia, Costa, Dos Santos Pinheiro \& Vaz Carneiro, 2009).

Smoking rates in Portugal are slightly decreasing in males and increasing in females (Borges et al, 2009) and probably the same pattern is happening among Portuguese immigrants. Rates of smoking for men are still extremely high, therefore, this study will focus on male Portuguese American immigrants who smoke or used to smoke in the past.

\section{Portuguese and health}

According to the US Census Bureau (2000) there are 1,773,691 people of Portuguese ethnic origin in the US. California alone contains 330,974, making it the largest Portuguese community in the country (World Lingo/Census 2000).

In spite of the presence of this large population, few studies have examined smoking among Portuguese in the US. Among all Latino countries, Portugal has the third highest rate of smoking among males (Muller \& Wehbe, 2008; WHO, 2006). The patterns of smoking among Portuguese immigrants in the U.S. are unknown, and this study attempts to fill this apparent gapin the literature.

Morrison and James (2009) studied Portuguese immigrants in Canada using a qualitative study design to investigate acculturation issues and how Portuguese immigrants behave when they acculturate. They found that first generation Portuguese do not acculturate well compared to second generation, which creates a source of stress for the family. The study also found that women are key negotiators when problems arise in the family. Adrian, Dini, MacGregor and Stoduto (1995) studied addiction behaviors among different female immigrants in Canada including Portuguese. They found that Portuguese women have lower rates of both alcohol and tobacco use than Canadian women. Clabots and Dolphin (1992) reported a project conducted in Rhode Island among several different ethnicities including Portuguese. They prepared a series of videos in specific languages that successfully instructed and motivated individuals to take better care of their health and seek access to medical services. Hence, Portuguese smokers may be receptive to smoking cessation messages.

The Smoking Cessation Behavior in Male Portuguese Californians study investigates the socio-demographic, social and health beliefrelated characteristics of smoking among a 
sample of Portuguese American males living in Southern and Central California. Health behaviors in this population have not been studied, and data on smoking is limited. The results of the current study can lead toward a more effective approach to smoking cessation in this population and to similar populations with a high rate of smoking among males.

\section{Smoking related factors}

Support for not smoking: The belief that having friends or close relatives that do not smoke may be one factor that can influence smoking behavior. However, Jepson, Harris, Platt and Tannahill (2010) found inconclusive results about social support and smoking in different populations.

Self efficacy to stop smoking: Theoretically, self-efficacy to stop smoking should lead to smoking cessation. Gwaltney, Metrik, Kahler and Shiffman (2009) explored the association with their meta-analysis of 50 studies on the topic. The authors found a weak negative association between self-efficacy and smoking behavior. The relationship, however, depends on when self-efficacy was assessed. Self-efficacy assessed right after an individual quits is a better predictor of quitting. In this study self-efficacy was assessed several months or years after the participants stopped smoking.

Locus of control: Individuals have two types of health locus of control, external or internal. External locus of control is when people think that health occurs by external forces (other, people, chance, spiritual reasons). Internal locus of control is when people assume that they are responsible for their health (Luszczynska \& Schwarzer, 2005). The connection between health locus of control and smoking has been studied in other populations with inconclusive results (Stuart, Borland \& Murray, 1994; Steptoe and Wardle, 2001) Bennet, Norman, Moore and Murphy (1997) found in a sample of 11,401 persons that those who think that health outcomes are produced by chance are more likely to be smokers and that ex-smokers had lower scores on the chance dimensions. In the review by Wallston and Wallston (1978), the authors suggest that health locus of control should be assessed for the sake of developing the right smoking cessation strategies or treatment.

\section{Methods}

This is a cross-sectional study designed to investigate psychosocial correlates of smoking cessation among a population of Portuguese American males living in Southern and Central California. This work is part of the Portuguese Study, which assessed the relationship of acculturation and other demographic and psychosocial behaviors of smoking in a convenience sample of male Portuguese immigrants. The study began with an informal community needs assessment conducted with key informants (Dos Santos, 1999).

\section{Study sample and data collection}

Study participants' eligibility was based on smoking status (current smokers who smoke one or more cigarettes a day and ex-smokers who quit for 6 or more months), age (18 years or older), and being of full Portuguese ancestry (either self or both parents born in Portugal). Two hundred and eight males of Portuguese origin defined either as smokers or ex-smokers living in Southern and Central California participated in the study. Participants were surveyed in the Divino Espirito Santo (DES Divine Holy Spirit) Portuguese Halls. DES halls are traditional clubs that promote spiritual and social celebration events for Portuguese immigrants in the US. Surveys were conducted during festivities at the DES halls in Artesia, Chino, Santa Clara, San Jose, and Tulare. At least 20 participants were interviewed in each location through a booth setup along with distribution of health promotion materials. In Chino and San Jose, the local Portuguese radio programs helped to promote the study. In Artesia, the local Portuguese television channel promoted the study. Participants provided informed consent approved by the Loma Linda University Institutional Review Board.

To assess time required for questionnaire completion, legibility, clarity of wording, and comprehension of the questions by this population, a pilot study was conducted in a 
sample of the population recruited from a Portuguese speaking Seventh-day Adventist church located in the city of Chino, California.

\section{Questionnaire}

The questionnaire was designed in English translated into Portuguese then translated again into English using standard back translation methodology (Geisinger, 1994). Men who met the inclusion criteria and were willing to participate were classified as smokers or exsmokers (dependent variable). Independent variables measured include age, employment, income, education, health beliefs, stress, social support and acculturation. A short 4-item version of the Perceived Stress Scale (PSS) was chosen to measure stress (Cohen, Kamarck \& Mermelstein, 1983). The PSS uses both a 14item scale and 10 and 4-item scales. The Cronbach's alpha for the 4-item scale was .72. In this study, the 4-item scale had an alpha of .83. Acculturation questions were taken from the 12-item acculturation scale "Short Acculturation Scale for Hispanics" (SASH), which has been successfully used to measure level of acculturation in Hispanics (Marin, Sabogal, Marin, Otero-Sabogal \& Perez-Stable, 1987). Both Marin's scale and the one used in this study had an alpha of .92. The support index for not smoking consisted of questions about how family, friends and work may influence smoking behavior (Venters, Kottke, Solberg, Brekke \& Rooney, 1990), and assess how much support for quitting participants receive from friends and significant others. The main question used in this study to evaluate social support for quitting was "How much support for quitting smoking do you have from your spouse?" The same question was asked about support from friends. Answers were on a Likert scale from 1 (low) to 5 (high).The 5-item Likert scale had a coefficient alpha .76 in the current study. The health belief questions assessed individual's beliefs about the harm to health caused by smoking, and whether they believed that smoking would cause illness (Jaen, Cummings, Zielezny \& O'Shea, 1993 and Rice, Cortes \& Malgady, 1996).

\section{Statistical Analyses}

Data were analyzed using SPSS 17.0 software. Basic descriptive statistics were preformed on all the variables. Variables were analyzed directly from the questionnaire, each question as one variable, or combined to form indexes like the acculturation index, support for not smoking index, and stress index.

ANOVA was used to check for mean differences in continuous variables according to smoking status. Chi-square was used to compare categorical variables according to smoking

Table 1

Male Portuguese Americans from Central and Southern California: Demographics and Smoking Variables $(\mathrm{N}=208)$

\begin{tabular}{lll}
\hline Variables, n (\%) & Ex-Smoker (n=67) & Smoker $(\mathbf{n = 1 4 1})$ \\
\hline Age - mean (SD) & $55.9(14.1)$ & $48.4(12.4)^{* *}$ \\
Currently employed & $26(38.8)$ & $37(26.2)$ \\
Married & $62(92.5)$ & $111(78.7)^{* *}$ \\
Less than high school ed. & $51(76.1)$ & $102(72.3)$ \\
Income $\leq 40,000 /$ year & $31(56.4)$ & $79(63.7)$ \\
Support Index - mean (SD) & $3.9(.9)^{* *}$ & $2.9(1.0)$ \\
Closest friend smokes & $20(30.3)^{* *}$ & $96(68.1)$ \\
Doctor controls health & $57(86.4)^{*}$ & $100(70.9)$ \\
Health by chance & $26(39.4)^{*}$ & $82(58.2)$ \\
Easy to quit smoking & $31(47.0)^{* *}$ & $15(10.6)$ \\
\hline$* \leq .05, * * \leq .01$ & &
\end{tabular}


status. The statistically significant factors from the bivariate analysis were then tested by logistic regression to determine their relationship with smoking status after controlling for other predictor variables. $\mathrm{P}$ values lower than 0.05 were considered statistically significant and adjustment was not made for multiple testing.

\section{Results}

The mean age for this group is about 50 years old (data not shown), and table 1 shows that non smokers are slightly younger $(\mathrm{p}<.01)$. After the regression analysis, however, age was not significantly related to smoking status as noted in Table 3. Other features of the participants in Table 1 shows that most of smokers are married, employed, have less than a high-school education and an annual income of less than $\$ 40,000$. Another variable negatively related to smoking behavior in table 1 was marital status ( $\mathrm{p}=.01$ ), but after further analysis the association was not confirmed.

Table 2, shows the bivariate and multivariate analysis of several variables and smoking status. These variables include high support index for not smoking $(\mathrm{p}<0.01)$, having a nonsmoking close friend $(\mathrm{p}<0.01)$, perception that doctors control health $(\mathrm{p}=0.02)$, disagreement with the belief that health occurs by chance $(\mathrm{p}=0.01)$, and belief that it is easy to stop smoking $(\mathrm{p}<0.01)$ (see Table 2). There was no relationship between stress index and the acculturation index with smoking status (data not shown).

Table 2

Association between demographic characteristics, stress, health beliefs and self efficacy and smoking status of male Portuguese Americans from Central and Southern California: Bivariate Logistic Regression and Multiple Logistic Regression analysis

\begin{tabular}{|c|c|c|c|c|}
\hline \multirow[t]{2}{*}{ Variables } & \multicolumn{2}{|c|}{ Bivariate Logistic Regression } & \multicolumn{2}{|c|}{ Multiple Logistic Regression } \\
\hline & OR & $95 \% \mathrm{CI}$ & AOR & $95 \% \mathrm{CI}$ \\
\hline Age & $.96^{* *}$ & $.93-.98$ & .95 & $.90-1.00$ \\
\hline Employment & $.56 * *$ & $.30-1.04$ & 1.11 & $.26-4.64$ \\
\hline Marital status & $.29 *$ & $.11-.81$ & .99 & $.22-4.38$ \\
\hline Education & 1.22 & $.62-2.38$ & 1.03 & $.32=3.38$ \\
\hline Income & .73 & $.38-1.40$ & .72 & $.24-2.17$ \\
\hline Support Index & $.34 * *$ & $.23-.50$ & $.37 * *$ & $.19-.71$ \\
\hline Closest friend smoke & $4.90 * *$ & $2.60-9.24$ & $3.27 *$ & $1.01-10.59$ \\
\hline Doctor control health $-\mathrm{n}(\%)$ & $.38 *$ & $.17-.85$ & 1.52 & $.43-5.36$ \\
\hline Health by chance & $2.13^{*}$ & $1.18-3.89$ & $4.27 * *$ & $1.56-11.65$ \\
\hline Easy to quit smoking & $.37 * *$ & $.26-.54$ & $0.09 * *$ & $.03-.30$ \\
\hline
\end{tabular}

In the multivariate analysis (Table 2) - after controlling for demographic variables, acculturation, and stress - ex-smoking status remained associated with having a high support index for not smoking $(\mathrm{p}<0.01)$, having a nonsmoking close friend $(\mathrm{p}=0.05)$, disagreement with the belief that health occurs by chance $(\mathrm{p}, 0.01)$ and the belief that it is easy to stop smoking $\mathrm{p}<0.01)$. The smoking status categories in the regression model predict the status of being a smoker as 1 and a nonsmoker as 0 .

\section{Discussion}

Smoking is globally one of the main modifiable risk factors for major chronic diseases such as heart disease and cancer. Therefore, there is a need for smoking cessation promotion worldwide and nationwide as $18.4 \%$ of Americans still smoke (Kaiser Family Foundation, 2011). It is advantageous to focus on populations with high rates of smokers like the Portuguese Americans by creating programs 
that are culturally sensitive. There are no available data showing the rate of smoking among Portuguese immigrants in America. However, the rate of smoking among American males is lower than Portuguese males when compared to smokers in Portugal, 20.7\% and $30.6 \%$ respectively (Kaiser Family Foundation, 2011 and Precioso et al, 2009). Considering Portuguese immigrants retain their smoking habits once they immigrate to the US - as they tend to socialize with persons of similar background, and tobacco use is a large part of their social interactions - it can be inferred that Portuguese males have a higher rate of smoking than American males.

In addition, there are no published programs or studies for the prevention or cessation of smoking in this population. Therefore, there is a need to know what factors affect this ethnic group in order to develop proper anti-smoking interventions. The main results of this study showed that having a high social support for not smoking, disagreement with the belief that health occurs by chance and self-efficacy to stop smoking are important factors to aid in smoking cessation.

Social support for quitting: In this study, social support to quit smoking from significant others and friends was associated with not smoking. Some information from Portuguese immigrants in shows that Portuguese women have a strong family influence (Morrison \& James, 2009) and are less likely to be smokers. Empowering them with smoking cessation skills such as information on smoking cessation methods (nicotine replacement therapy, behavior therapy and medication) could indirectly influence their counterparts to stop smoking.

Self efficacy: The main question used to assess self-efficacy was if participants found it easy or difficult to quit smoking. In this study, $74.5 \%$ of the smokers found it difficult compared with $28.0 \%$ of ex-smokers. This can be interpreted as low self-efficacy to stop smoking prevents people from quitting. These results resemble the findings of Sabogal, Otero-Sabogal, PerezStable, Marin and Marin (1989) among
Hispanics where high self efficacy is negatively related to smoking.

Further studies should be conducted to confirm the influence of self-efficacy on quitting smoking. In this study, however, self efficacy was inversely related to smoking. Therefore, when developing smoking cessation programs for this population, self efficacy should be emphasized and, specially, the current availability of pharmacological aids such as nicotine replacement therapy, bupropion, and varenicline (Jorenby, D.E., Hays, J.T., Rigotti, N. A., Azoulay, S., Watsky, E. J., Williams, K. E., Billing, C.B., Gong, J., Reeves, K. R., 2006; Gonzales, D., Rennard S. I., Nides, M., Oncken, C., Azoulay, S., Billing, C. B., Watsky, E. J., Gong, J., Williams, K. E., Reeves, K. R., 2006).

Locus of control: Most smokers in this study hold the belief that health occurs by chance (external locus of control), meaning they probably do not believe smoking is related to disease. On the other hand, those who believe that health does not occur by chance are more likely to be nonsmokers. This is also in line with results of a study among Hispanics related to locus of control. Valentine and Godkin (2008) found that external locus of control was related to barriers to health behavior change among Hispanics. If a person does not feel responsible for his own health, he will be less likely to change his behavior. This perception of an external locus of control may be associated with the prevalence of Christianity among Portuguese and Hispanics, which considers disease related to spiritual issues and not behavior. Even though the issues of health locus o control are not clear, it is important to note that this sample showed smokers more likely to have an external locus of control, thus believing that external forces, not their own behavior, are responsible for their health. This should encourage the development of more culturally sensitive information and strategies to convince this population of the connection between smoking behavior and disease.

\section{Limitations}

This study utilized a convenience sample with a 
cross-sectional design, therefore, we cannot confirm temporal precedence for the relationships between the variables studied. there is low external validity On the other hand, since there are no published smoking related studies among the Portuguese in the US, this study can shed some light on the smoking characteristics of this population and provide a starting point for further studies and programs for Portuguese immigrants in North America.

\section{Conclusion}

Despite a downward trend of smoking in the US, rates of many immigrants remain high reflecting rates from their country of origin. Findings from this study might demonstrate that immigrants might maintain a prevalence of smoking that is similar to that ot their country of origin.. Having insight into these smaller and often overlooked sub-populations that continue to smoke at higher rates may assist smoking cessation programs for such populations. Also, the result about locus of control might be something that should be explored in other populations when there may be a tradition to consider external factors responsible for disease rather than behavior.

Smoking behavior data of Portuguese American immigrants to the US is limited. Additionally, there are only a few studies that address the overall health needs of this population. Therefore, this study should be followed by further research to understand the characteristics of this population not only related to smoking but also to other health behaviors and diseases.

Further studies should be performed in other areas of Portuguese immigration in North America, such as Massachusetts, Rhode Island and Canada, to confirm the validity of these results.

Other aspects to be investigated are the smoking behavior of Portuguese women in the US compared to women living in Portugal, and the differences in smoking habits between first and second-generation Portuguese immigrants.

One of the most important lessons to gain from this study is that better understanding of this population facilitates the development and implementation of anti-smoking programs for them. Any program targeting smokers in this group should involve the family as a whole and consider social environment and pressures. Also, more information in both English and Portuguese should be produced and disseminated explaining the close relationship between smoking and illness, especially targeting males. Greater focus should also be placed on self-efficacy. Smokers should realize that smoking cessation today is easier than in the past, with more tools, support, medication, , anti-smoking laws, smoke-free settings, and less smoking promotion in the media.

\section{Acknowledgements}

Thanks to the members of the California Portuguese community, specially Dr. Ramiro Dutra, $\mathrm{PhD}$, who volunteered to check the back translation of the questionnaire; to Vasco Mattos $\dagger$ and Osvaldo Palhinha from the Radio and TV Artesia for help in advertising; and to the directors of the DES Portuguese Halls in Artesia and Chino, Clube do Benfica in San Jose and the Portuguese Athletic Club in Tulare for allowing the use of their facilities for this study.

\section{References}

American Lung Association (2008) Taken on 06.29.2010 from website: http://www.lungusa.org/stopsmoking/about-smoking/facts-figures/hispanics-and-tobacco-use.html

Adrian, M., Dini, C.M., MacGregor, L.J., \& Stoduto, G. (1995). Substance use as a measure of social integration for women of different ethno cultural groups into mainstream culture groups in a pluralistic society: The Example of Canada. The International Journal of the Addictions, 30(6), 699-734.

Bennett, P., Norman, P., Moore, L., Murphy, S. \& Tudor-Smith, C. (1997). Health locus of control and value for health in smokers and nonsmokers. Health Psychology, 16(2), 179-182. 
Dos Santos,H., Tonstad,S., Montgomery, S., Paalani, M. \& Faed, P. / Californian Journal of Health Promotion 2011, Volume 9 , Issue 2, 68-76

Borges M., Gouveia M., Dos Santos Pinheiro L., Paulo, S. \& Vaz Carneiro, A. (2009) The burden of disease attributable to smoking in Portugal. Revista Portuguesa de Pneumologia, 15(6), 9511004.

Capewell, S \& O'Flaherty, M. (2008). What explains declining coronary mortality? Lessons and warnings. Heart, 94, 1105-1108.

Centers for Disease Control and Prevention, 2010. Vital Signs: Current Cigarette Smoking Among Adults Aged $\geq 18$ Years - United States, 2009. Morbidity and Mortality Weekly Report 59(35):1135-40.

Clabots, B.C. \& Dolphin, D. (1992) The Multilingual Video Tape Project: Community involvement in a unique health education program. Public Health Reports, 107(1), 75-80.

Cohen, S., Kamarck, L. \& Mermelstein, R. (1983). A global measure of perceived stress. Journal of Health and Social Behavior, 24(4), 385-396.

Dos Santos, H.F., (1999). Influence of acculturation and psychosocial predictors on smoking status of Portuguese immigrant males in California, using the Transtheoretical Model of Behavior Change; Dissertation defense for the doctoral program in public health published by Loma Linda University.

Geisinger, K. F. (1994). Cross-cultural normative assessment: Translation and adaptation issues influencing the normative interpretation of assessment instruments. Special Section: Normative assessment. Psychological Assessment, 6(4), 304-312.

Gonzales, D., Rennard S. I., Nides, M., Oncken, C., Azoulay, S., Billing, C. B., Watsky, E. J., Gong, J., Williams, K. E. \& Reeves, K. R., (2006). Varenicline, an $\alpha 4 \beta 2$ Nicotinic Acetylcholine Receptor Partial Agonist, vs. Sustained-Release Bupropion and Placebo for Smoking Cessation. Journal of the American Medical Association, 296(1), 47-55.

Gwaltney, C. J., Metrik, J., Kahler, C.W. \& Shiffman, S. (2009) Self-efficacy and smoking cessation: A meta-analysis. Psychology of Addictive Behaviors, 23(1), 56-66

Kaiser Family Foundation (2011). From website: statehealthfacts.org. Accessed on March 31, 2011

Jaen, C.R., Cummings, K.M., Zielezny, M. \& O'Shea, R. (1993). Patterns and predictors of smoking cessation among users of a telephone hotline. Public Health Reports, 108(6), 772-8.

James, S., Navara, S. G., Clarke, J. N. \& Lomotey, J. (2005). An inquiry into the "Agonies" (agonias) of Portuguese Immigrants from the Azores. Hispanic Journal of Behavioral Sciences, 27, 547-564.

Jepson, R.G., Harris, F.M., Platt, S. \& Tannahill, C., (2010). The effectiveness of interventions to change six health behaviors: a review of reviews. BMC Public Health, 10, 538-553.

Jorenby, D.E., Hays, J.T., Rigotti, N. A., Azoulay, S., Watsky, E. J., Williams, K. E., Billing, C.B., Gong, J. \& Reeves, K. R., (2006). Efficacy of Varenicline, an $\alpha 4 \beta 2$ Nicotinic Acetylcholine Receptor Partial Agonist, vs Placebo or Sustained-Release Bupropion for Smoking Cessation. Journal of the American Medical Association, 296(1), 56-63

Luszczynska, A., Schwarzer, R. (2005) Multidimensional health locus of control: Comments on the construct and its measurement. Journal of Health Psychology, 10, 633-642.

Marin, G., Sabogal, F., Marin, B.V., Otero-Sabogal, R. \& Perez-Stable, E.J., (1987). Development of a short acculturation scale for Hispanics. Hispanic Journal of Behavior Science 9(2):183-205.

Muller, F \& Wehbe, L. (2008) Smoking abd smoking cessation in Latin America: A review of the current situations and available treatments. International Journal of Chronic Obstructive Pulmonary Diseases, 3(2) 285-293.

Morison, M. \& James, S. (2009) Portuguese Immigrant Families: The impact of acculturation. Family Process, 48(1), 151-165).

Precioso J., Calheiros, J., Pereira, D., Campos, H., Antunes, H., Rebelo, L. \& Bonito, J. (2009) Prevalence and smoking trends in Portugal and Europe. Acta Medica Portuguesa. 22(4), 335-48.

Rice, V.H., Cortes, D.E. \& Malgady, R.G. (1991) Acculturation and mental status among Hispanics Convergence and new directions for research. American Psychologist, 46(6), 585-587.

Sabogal, F., Otero-Sabogal, R., Perez-Stable, E.J., Marin, B.V. \& Marin, G. (1989) Perceived SelfEfficacy to avoid cigarette smoking and addiction: Differences between Hispanics and nonHispanic whites. Hispanic Journal of Behavioral Sciences, 11(2), 136-147. 
$6^{\text {th }}$ National Conference of Nursing Oncology, 2006. Lisbon, Portugal. From website: www.cienciahoje.pt/index accessed on June 21, 2011.

Steptoe, A., Wardle, J. (2001) Locus of control and health behavior revisited: A multivariate analysis of young adults from 18 countries. British Journal of Psychology 92(4): 659-672.

Stuart, K., Borland, R., \& Murray, N. (1994). Self-efficacy, health locus of control and smoking cessation. Addictive Behaviors, 19(1), 1-12.

Surgeon General Report (2010). A Report of the Surgeon General: How Tobacco Smoke Causes Diseases. http://www.surgeongeneral.gov/library/tobaccosmoke/report/index.html

U.S. Census Bureau Report (2000). Number of people of Portuguese origin in the U.S. Census 2000. Retrieved on April 10, 2006, from http://www.census.gov/

Valentine, S.R. \& Godkin, J. (2008) Locus of Control, Acculturation, and Wellness Attitudes. Social Work in Public Health, 23(5), 73.

Venters, M. H. , Kottke, T. E. , Solberg, L. I. , Brekke, M. L. \& Rooney, B. (1990) Dependency, social factors, and the smoking cessation process: the doctors helping smokers study. American Journal of Preventive Medicine, 6(4), 185-193.

Wallston, B. S. \& Wallston, K. A. (1978). Locus of control and health: A review of the literature. Health Education Monographs, 6, 107-117.

World Health Organization. WHO Report on the Global Tobacco Epidemic, 2008: The MPOWER Package. Geneva: World Health Organization, 2008.

WHO - World smoking rates. www.who.int/countries/en/- Retrieved on August 23, 2011.

World Lingo (About Census 2000) http://www.worldlingo.com/ma/enwiki/en/Portuguese_American. Retrieved on June 29, 2010.

\author{
Author Information \\ Hildemar Dos Santos, MD, DrPH, Assistant Professor* \\ Loma Linda University \\ School of Public Health, Health Promotion Department \\ 24951 N. Circle Dr. \# 1511 \\ Loma Linda, CA 92350 \\ Telephone: (909)558-8746 \\ Fax: (909)558-0471 \\ Email: hdossantos@1lu.edu \\ Serena Tonstad, MD, PhD, Professor \\ Loma Linda University \\ School of Public Health, Health Promotion Department \\ Susanne Montgomery, PhD, Professor \\ Loma Linda University \\ School of Public Health, Health Promotion Department \\ Michael Paalani, DrPH, MS, Research Assistant \\ Loma Linda University \\ School of Public Health, Health Promotion Department \\ Pegah Faed, MPH, DrPH (c) \\ Loma Linda University \\ School of Public Health, Health Promotion Department \\ * corresponding author
}

